\title{
A method for displaying a graphical system design
}

\author{
Mukhammet Fakhratov ${ }^{*}$, Sergey Sinenko ${ }^{1}$, and Mohammad Sharif Akbari ${ }^{1}$ \\ ${ }^{1}$ Moscow State University of Civil Engineering, 129337, 26 Yaroslavskoye sh., Moscow, \\ Russia
}

\begin{abstract}
The methods of displaying the design system are considered. The interpretation of the design model of buildings and structures is given. Designing is usually considered as a set of operations performed by the designer when creating a project and functions in other areas. The design process is an adequate representation of the project for the construction of an object in all conditions. It is described by design routes, design operations algorithms, including tools for evaluating custom indicators, methods for determining design resources. This is an informational labour process. Among the many characteristics of design systems, the structure occupies a special position. The structure is the most general and most stable characteristic of the system, invariant with respect to the specific execution of elements and state. The structure reflects the general, essential and stable properties of the system. Many structural elements that perform one elementary action form an organizational module. An organizational module is an organizational system module. The introduced concepts allow us to define organizational management as a process of redistributing modules of an organizational system by technological and information modules.
\end{abstract}

\section{Introduction}

The fundamental changes in construction, production have occurred over time, including other cases, the construction design is influenced. The strategy for the innovative development of the construction industry until 2030 indicates many design problems that affect the quality of the design documentation being developed and the time of its preparation. Design mismatch with modern requirements arose for several reasons, which include a sharp reduction in the number of qualified personnel, an increase in the number of

\footnotetext{
*Corresponding author: fahratov@mail.ru
} 
new design firms being created, unsatisfactory and costly information support for project activities, etc.

The influence of the timing and quality of the design and estimate documentation on the implementation of the entire construction project is due to the existing production organization system. Ensuring the necessary efficiency of the design organization is an essential condition for timely and high-quality construction.

The project organization, as a key participant in the design of construction, has its specific activities. It includes the simultaneous development of several projects at different stages of the life cycle, the organization of the work of specialists of different departments, the nature of design facilities, the formed system of pay, the impact of deadlines and quality of design for construction, high competition in the field of design services, etc. Specific design features include the creative reworking of a significant and constantly updated array of regulatory, methodological, technological and organizational information.

The development of construction design cannot be imagined without the modern stage of development of computer-aided design (CAD) systems. These technologies make it possible to organize production in such a way that the work processes performed are distributed in time and territorial frames, that is, interaction takes place in a virtual environment.

In modern conditions, ideas about the boundaries of the organization are lost, the external environment ceases to be external, and becomes the existing space of virtual business systems that penetrate each other.

Designing is usually considered as a set of operations performed by the designer when creating a project and functions in other areas. This is an informational labour process. It includes operation, reception, action (preliminary, main, verification), movement - having different characteristics (duration, labour, resources, etc.), place and implementation methods. Fig.1.

In this case, the design refers to the development of integrated technical documentation (project) containing a feasibility study, calculations, drawings, layouts, estimates, explanatory notes and other materials necessary for the construction or reconstruction of buildings and structures and their complexes.

The design process is an adequate representation of the project for the construction of an object in all conditions. Design routes, design operations algorithms, including tools for evaluating custom indicators, methods for determining design resources, describe it. Forms of description are maps, circuits, matrix, linear and network models, etc.

\section{Materials and Methods}

Studying the design process shows that it has a hierarchical, iterative nature. The iterative nature is determined by the absence of an algorithm by which synthesis can be carried out immediately (Construction documentation) [3-15]. 


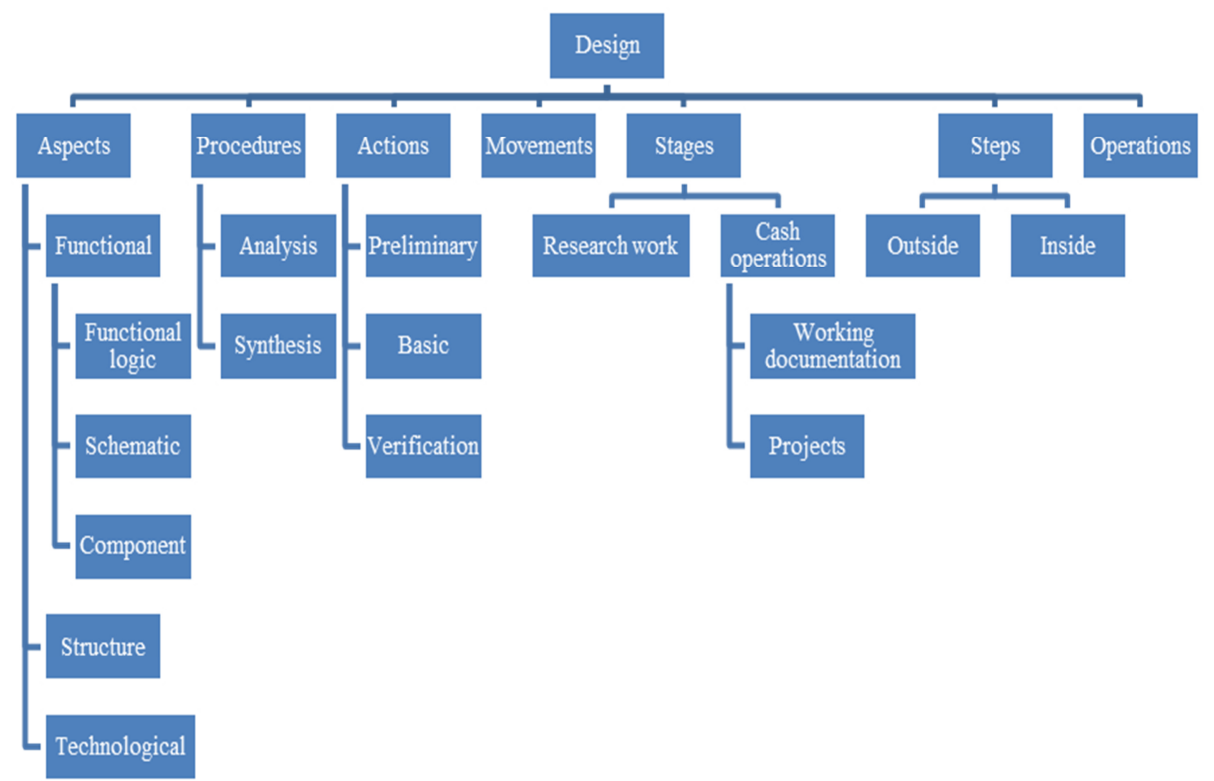

Fig. 1. Technological design system.

Design can be divided into parts according to the Item of Documentation (Construction documents), for example:

Table 1. List of documentation

\begin{tabular}{|c|l|}
\hline № & List of documentation \\
\hline \multicolumn{2}{|c|}{ Section 1 General } \\
\hline 1 & Source and permit documentation \\
\hline 2 & General explanatory note \\
\hline 3 & Specifications for design and construction \\
\hline Section 2 Architectural - building part \\
\hline 4 & General plan \\
\hline 5 & Architectural planning solutions \\
\hline 6 & Constructive solutions and calculations \\
\hline 7 & Vertical transport. Elevators \\
\hline Section 3 Engineering Equipment and Technology \\
\hline 8 & Electrical part \\
\hline
\end{tabular}




\begin{tabular}{|c|c|}
\hline 9 & Heating supply \\
\hline 10 & Water supply. Water disposal and fire fighting \\
\hline 11 & Ventilation and air conditioning, heating, and cooling \\
\hline 12 & Security Systems and Telecommunications \\
\hline 13 & $\begin{array}{l}\text { Instrumentation and automation. An automated system of supervisory control and } \\
\text { management }\end{array}$ \\
\hline 14 & Design of security and protective de-hydration system \\
\hline 15 & $\begin{array}{l}\text { Engineering and technical measures on civil defense and the project of a liar complex on the } \\
\text { roof of the building }\end{array}$ \\
\hline 16 & Environmental protection \\
\hline 17 & Energy efficiency \\
\hline 18 & Technological solutions \\
\hline \multicolumn{2}{|c|}{ Section 4 Outdoor Networks } \\
\hline 19 & The master plan of external networks \\
\hline 20 & Power supply \\
\hline 21 & Heating \\
\hline 22 & Water supply. Sanitation \\
\hline 23 & Radio installation. communication \\
\hline 24 & Drain \\
\hline \multicolumn{2}{|c|}{ Section 5 Construction Organizations } \\
\hline 25 & $\begin{array}{l}\text { Project for the organization of construction of the aboveground and underground parts of the } \\
\text { building }\end{array}$ \\
\hline 26 & Additional materials \\
\hline
\end{tabular}

The features of the organization and construction technology have an impact on the design process. These include:

1. The design object is structures, complexes;

2. The construction process, which is considered in "time" and in "space";

3. Solvable tasks that are closely interconnected with each other, while solving particular problems does not always lead to an improvement in the whole organization and construction technology, and a number of others. 
Designing is an activity in a multi-level space in which the applied tools and techniques do not function on the same plane, much less pass along the same line. The starting point for the formation of this spatial form is arbitrary. Moreover, the designer also does not know the number and nature of individual procedures on the way from the starting point to the final result. The appearance of a visual form can occur instantly, intuitively or as a result of a long search, analytically or unconsciously.

Today, the development of various projects is engaged not one designer, but a group or a whole design institute. Figure 2.

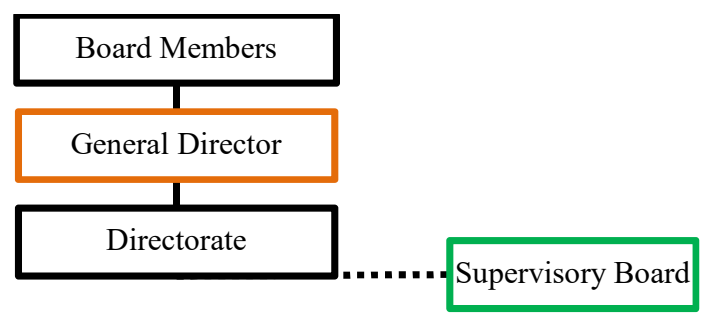

Functional level

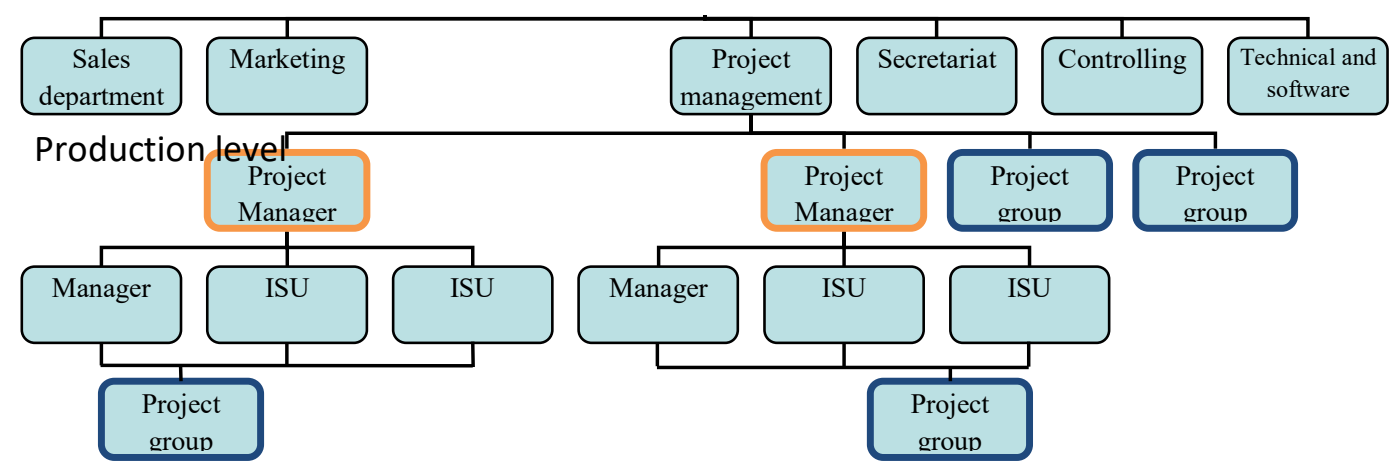

Fig. 2. Organizational design system.

When a group of designers works on one project, first, it is necessary to ensure the effective management of individual drawings. This means that the compatibility of the transmitted data for various programs is vital, to ensure their consistency and timely updating. This problem is solved in different ways, for example, by forming a certain information model, all changes in which are automatically transferred to the associated flat drawings. At the same time, designers, working on their model site, automatically receive all project changes from their colleagues [3-15].

\section{Results}

Among the many characteristics of design systems, the structure occupies a special position. This is due to the fact that the structure is, firstly, the most general and, secondly, the most stable characteristic of the system, invariant with respect to the specific execution 
of its elements and changes in its state, i.e. structure reflects the most general, essential and at the same time stable properties of the system. Fig. 3.

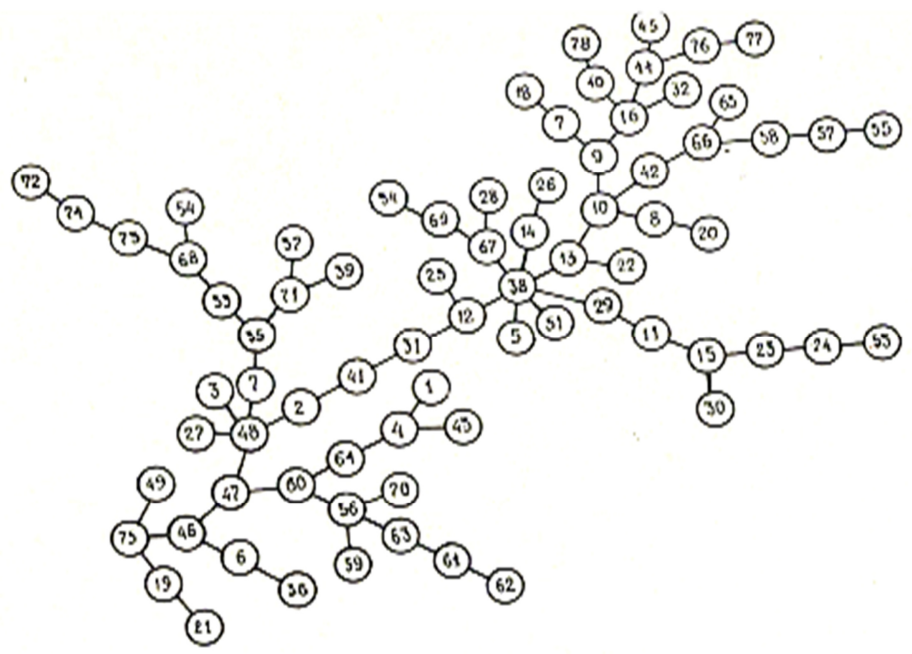

Fig. 3 The organizational structure of the design system (conditional mapping).

By identifying objective patterns that exist in organizational structures, the head of the institute is given to solve the issues related to the membership of the structural units (Figure 4).

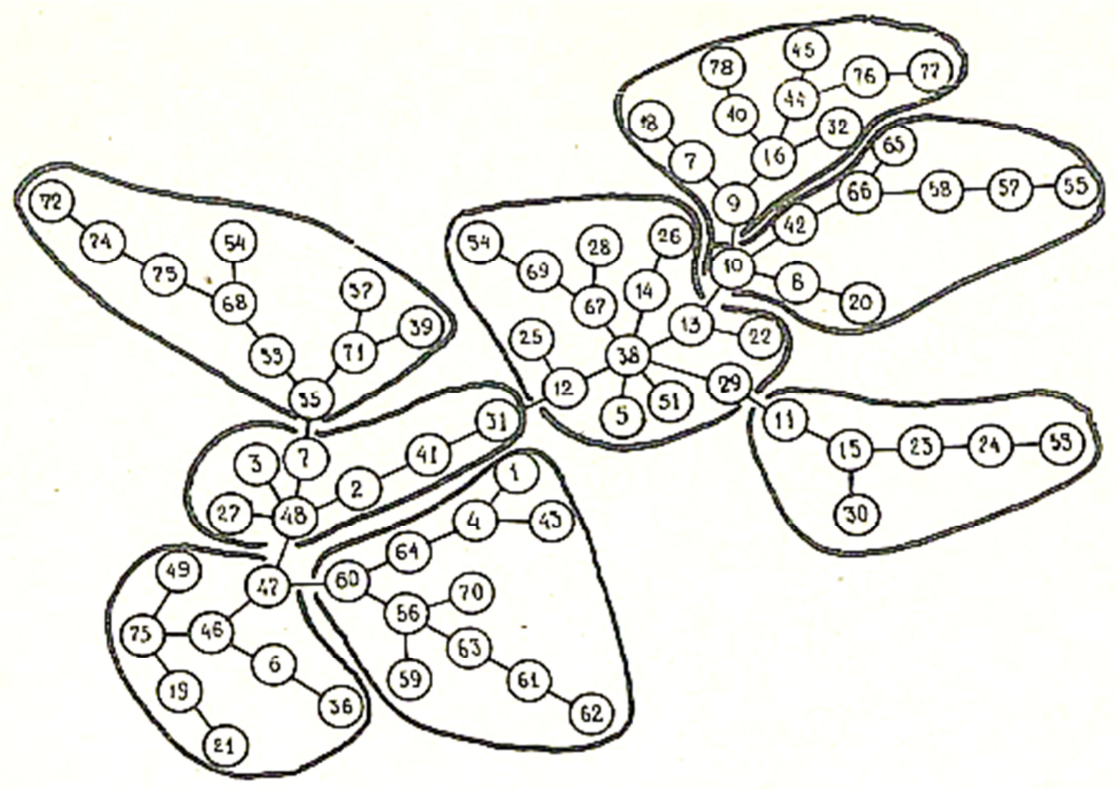

Fig. 4. The division of the organizational structure. The option of dividing into small structural units. 
In the process of production and social activities, the structural elements of the organizational system cannot continuously change its role. The change of the role can take place only when the structural element has played to the end the simplest, but quite complete production or social role. As such an elementary production role, it is advisable to adopt the maximum autonomous sequence of elementary actions.

Such a maximum autonomous sequence is an indivisible quantum of resource transformation as a separate structural element (module) of the organizational system.

A resource transformation is any change in the quantity or quality of a resource at a given point in space.

The elementary transformation will be called such a transformation, which has a clearly expressed beginning \& end and cannot be artificially dissected into simpler transformations with a clearly expressed beginning and end. Elementary conversion of resources, performed by a person, we call elementary action.

As a rule, elementary action is carried out by one structural element of the organizational system. However, some of these actions require the involvement of several structural elements at the same time.

Many structural elements that perform one elementary action form an organizational module.

Thus, the organizational module is a generalized executor of elementary actions, consisting of one and in some cases several or even many structural elements of the organizational system.

Therefore, the organizational module is the module of the organizational system.

The technological and information module can only function when the corresponding organizational module is connected to it.

The organizational system interacts with resources only by connecting the organizational modules of this system to technological and information modules.

The introduced concepts allow us to define organizational management as a process of redistributing modules of an organizational system by technological and information modules.

Then there is the elimination of a lot of connectivity of the top by maintaining a connection with the top, in which the "meaningful share" of the top in question is greater than in the other related adjacent peaks (Figure 5). This is how a network is built that shows the structure of the system.

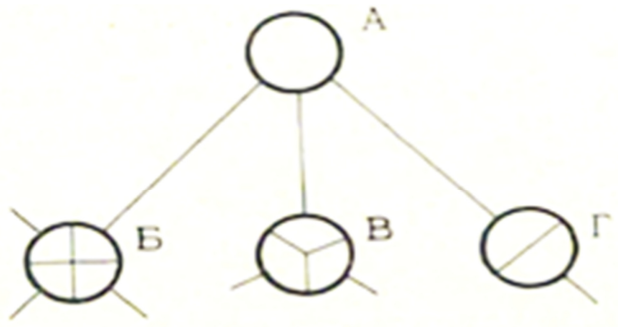

Fig. 5. Communication units. 
This approach is implemented in the form of a graphical display of the design system pic.4.

\section{Discussion}

The construction of a model of self-organization of the design system within a certain organization (project institute) is carried out in the following order. First, there is a ranking of units and groups by the significance of the tops, which correspond in this case degrees of the tops of the graph. The degree of the vertex of the graph is calculated as the number of links converging to any unit (top of the graph) from the rest of the groups and units of the field (from the other tops of the graph). The units are in the appropriate ranking table. The ranking is done on the computer.

\section{Conclusions}

In accordance with the accepted definitions and the described certain manipulations, it is possible to imagine and describe the design system of the construction object.

\section{References}

1. V. P. Ignatov, Modeling of building design based on intelligent technologies, (2012)

2. F. Engels, Ludwig Feuerbach and the end of German classical philosophy (2011)

3. S. Sinenko, MATEC Web of Conferences 112, 09007 (2017) DOI: 10.1051 / matecconf / 201711209007.

4. S. Sinenko, A. Slavina, MATEC Web Conf. Volume 106, 2017 International Science Conference SPbWOSCE-2016 "SMART City" 080168 Organization and Planning of Construction Works and Municipal Facilities 23 May 2017, https://doi.org/10.1051/matecconf/20171060801623 May 2017

5. V.P Grakhov, S.A. Mokhnachev, I.A . Paramonov, Mod. Probl. Sci. Educ. 1, (2015)

6. Yu.V Kuznetsov., E.V. Melyakova, Sci. j. NRU ITMO. 4, 248-256 (2015)

7. V.P. Abarykov, Optimization of the design system in construction (2000)

8. A.A. Bolshakov, S.N. Volkov, Vestnik MGSU 2013.,11, 218 - 225

9. S.N. Bolshakov, Vestnik MGSU, 13, 287-294 (2013)

10. S.N. Bolshakov System engineering design of virtual organizational structures of enterprises of the building complex ... candidate of technical sciences, (2013)

11. A.V. Kataev, Virtual business organizations, (2009)

12. T. I. Markova, L.A. Stroganova, Bull. Volga Un.. V.N. Tatishchev, 6, 40-45 (2014)

13. A.Yu. Slavina, BST Magazine 4, 2018.

14. S. N. Bolshakov, S. A. Sinenko., A. Yu. Slavina, J. Ind. Civ. Engin. 8, 87-91 (2016)

15. M. Warner., M. Witzel, Virtual Organizations. New forms of doing business in the 21st century, (2005) 